\title{
Corporate Liability and Compensation Following the Deepwater Horizon Oil Spill: Is There a Need for an International Regime?
}

Stephanie Theodotou*

DOI: $10.21827 / 5 b 51 \mathrm{~d} 56596663$

\author{
Keywords \\ ENVIRONMENT; OIL SPILL; LIABILITY REGIME: DEEPWATER HORIZON
}

\begin{abstract}
The purpose of this article is to assess the effectiveness of the current fragmented legal framework regarding corporate liability and compensation following oil spills from offshore installations, in light of the Deepwater Horizon oil spill. It evaluates whether Deepwater Horizon has signalled the need to adopt a uniform international regime, which will regulate compensation and liability concerning oil spills from offshore oil installations. The first part of this article provides the factual background of the Deepwater Horizon oil spill, with an emphasis on the corporate liability and compensation issues that arose in this incident and the response by the U.S. Government. The second part evaluates the effectiveness of the current three-tiered system of compensation in the oil tanker industry, as well as the supplementary voluntary agreements thereto, and assesses whether this legal framework could be adopted to the regime governing oil spills from offshore oil installations. It notes the stark contrast between oil spills from oil tankers and oil spills from offshore oil installations, in that an oil tanker's maximum storage capacity is known which makes the risk of potential spillage calculable. In contrast, it is impossible to make such a calculation for oil spills resulting from offshore oil installations since, although the storage capacity of the installation is defined when it is constructed, the amount of oil that can be spilled directly from the well drilled into the marine environment is unpredictable. The third part discusses the prospects for adopting an international civil liability and compensation regime governing oil spills from offshore installations, with reference to several international and regional attempts that have been made to establish an efficient regime and provides proposals for an efficient and effective international regime.
\end{abstract}

\section{Introduction}

The purpose of this article is to assess the effectiveness of the current framework regarding corporate liability and compensation following oil spills from offshore installations. Has Deepwater Horizon signalled the need for the international legal community to cooperate to adopt and enforce a regime tackling corporate liability and

Stephanie Theodotou is a Practicing Lawyer and a Qualified Mediator in Cyprus. Theodotou would like to express her gratitude to Prof. David M. Ong for his invaluable feedback and comments on previous drafts, and for sharing knowledge and expertise that greatly assisted her research. Theodotou would also like to express her gratitude to Prof. Maria Lee for her valuable guidance and feedback on earlier drafts of this article. Disclaimer: The statements made in this article are exclusively the author's own personal and/or academic views and are not intended to, nor should they, be attributed to any government body and/or organisation and/or otherwise. 
compensation following oil spills from offshore oil installations applicable on an international basis? The overarching thesis of this article answers this question in the affirmative, since such a regime would ensure prompt, adequate and effective compensation, regardless of the economic power of the State subjected to the oil spill. On the global scale, there is no implemented or enforceable agreement tackling such spills. While there have been attempts to adopt and enforce such a regime, these are arguably insufficient because, for instance, they are not applicable on a worldwide basis, or because they have received an inadequate amount of signatory State Parties in order to enable the legal instruments to enter into force.

This article begins with a factual background of In Re: Oil Spill by the Oil Rig "Deepwater Horizon" in the Gulf of Mexico, on April 20, 2010. ${ }^{1}$ It highlights BP's corporate liability and compensation issues in the manner it responded to the incident. ${ }^{2}$ For the purposes of this article, given the complexity and the magnitude of the issues involved in this case, liability will be assessed as if BP was the sole responsible party in Deepwater Horizon with the intention of conducting a deeper evaluation. ${ }^{3}$ It will be argued that BP's response was rather superficial, because it prioritised its reputation in accepting liability for the incident. Contrastingly, the U.S. Federal Government has responded in a manner superior to that of BP and made significant claims against the oil giant. In an oil spill of such magnitude as Deepwater Horizon, it took a powerful State and prolonged litigation with negotiation to respond; would such responses differ had the incident occurred in a less economically developed State?

The second part of this article emphasises the contrast that, whilst there is a global regime regulating civil liability for pollution damage by oil tankers, there is no uniform and universal regime regulating oil spills from offshore oil installations. It provides a solid overview of an integrated three-tiered regime for the oil tanker industry, followed by supplementary voluntary agreements. Will unifying the two systems be the ideal solution to the issue facing the offshore oil industry? Whilst there are strong positives in the oil tanker regime, there are arguably notable negatives about it. Most importantly, an oil tanker's maximum storage capacity is known and thus the risk of potential spillage is calculable. This is not the case for offshore oil installations since, although their storage capacity is defined at their construction stage, it is impossible to determine the amount of oil that can be spilled directly from the wells drilled into the marine environment.

Finally, this article focuses on the prospects for adoption of an international civil liability and compensation scheme for offshore oil pollution. This encompasses the international and regional attempts made to establish an efficient regime. Therefore, the answer to the question of whether there is an urgent need to implement an international regime mimics a double-edged sword; on the one hand, having a global regime will add efficacy and effectiveness in the regulation of offshore oil production. On the other hand, the global 'appetite' required to build such a regime seems to be lacking. Nevertheless, how would BP's response differ had such a regime been in place at the time Deepwater Horizon occurred? Numerous proposals will be presented to conclude this work.

\footnotetext{
United States District Court, Eastern District Louisiana, In Re: Oil Spill by the Oil Rig "Deepwater Horizon" in the Gulf of Mexico on April 20, 2010 MDL No. 2179 (2011).

2 Corporate liability and civil liability are used interchangeably in this article.

3 U.S. Department of Justice, Office of Public Affairs, Attorney General Eric Holder Announces Civil Lawsuit Against Nine Defendants for Deepwater Horizon Oil Spill, 15 December 2010, at $<$ http://www.justice.gov/opa/pr/attorney-general-eric-holder-announces-civil-lawsuit-against-ninedefendants-deepwater> (accessed 12 May 2018: See the U.S. Department of Justice civil lawsuit filed on $15^{\text {th }}$ December 2010 that identified nine defendants for the Deepwater Horizon Oil Spill: BP, two Anadarko defendants, MOEX Offshore 2007, Triton Asset Leasing GMBH, three Transocean defendants, and QBE Underwriting Ltd/Lloyd's Syndicate 1036.
} 


\section{Case Study: In Re: Oil Spill by the Oil Rig "Deepwater Horizon" in the Gulf of Mexico, on April 20, 2010}

Deepwater Horizon blowout... spewed nearly five million barrels, making it the world's largest accidental marine oil spill. ${ }^{5}$

The escape of hydrocarbons from the Macondo well, of which BP was the designated operator, caused an explosion and fire that destroyed the Mobile Offshore Drilling Rig Deepwater Horizon around fifty miles from the Mississippi River delta, killing eleven workers and causing widespread leakage of five million barrels of oil into the Gulf of Mexico, reaching Louisiana, Alabama, Florida and Texas. The spillage continued for one hundred and fifty-two days until the well was permanently sealed, but necessitated a U.S.' government response 'unprecedented in size, duration, and expense. ${ }^{6}$

\section{A. BP: corporate liability and compensation issues}

BP made testaments that it will pay all 'legitimate' claims, implying a willingness to waive the liability cap under the U.S. Federal Oil Pollution Act 1990 (OPA) 'but not lose sight of it. ${ }^{77}$ However, provided that numerous Congress members felt uncertain whether claims beyond BP's liability limit will suffice, President Obama exerted enormous pressure on $\mathrm{BP}$ to 'set aside whatever resources are required... as a result of [BP's] recklessness ${ }^{8}$ but also to set up an independent claims facility for victims. Consequently, BP established a $\$ 20$ billion irrevocable Trust financed by incremental payments, to facilitate valid individual and business claims under the Gulf Coast Claims Facility (GCCF). ${ }^{9}$

Arguably, the GCCF was insufficient, since the total number of claims, and hence the total amount of payable compensation, was almost impossible to calculate given the magnitude of the spill and the uncertainties associated with it. Nevertheless, the overall efforts by BP to pay compensation prompted the Congressional Research Service to report that BP accepted liability in Deepwater Horizon through the paying of OPAcompensable and OPA non-compensable claims, but for which BP could be liable for to satisfy harmed individuals, businesses and States. ${ }^{10}$ This, coupled with BP's 'moral

4 U.S. Judicial Panel on Multidistrict Litigation, In Re: Oil Spill by the Oil Rig Deepwater Horizon" in the Gulf of Mexico, on April 20, 2010, 'Transfer Order', 10 August 2010, at <http://www.laed.uscourts.gov/ sites/default/files/OilSpill/Orders/MDL_Transfer_Order.pdf> (accessed 12 May 2018) [hereinafter 'Transfer Order'].

5 Santore, J, "The Gulf of Oil" 218 National Geographic (2010) 28, 30.

6 U.S. District Court Eastern District of Louisiana, Complaint of the United States of America $v$ BP, Case 2:10-cv-04536, 2, 15 December 2010, at <https://www.epa.gov/sites/production/files/201310/documents/deepwater-cp121510.pdf $>$ (accessed 12 May 2018).

7 The Economist, Black storm rising, 6 May 2010, at <http://www.economist.com/node/16059982> accessed 12 May 2018.

8 White House, Obama, B, Remarks by the President to the Nation on the BP Oil Spill, 15 June 2010, at $<$ https://obamawhitehouse.archives.gov/the-press-office/remarks-president-nation-bp-oil-spill> accessed 12 May 2018.

9 University of Essex, Ong, DM, REPORT: Remedying Oil Spills in the Niger Delta: Systemic Failure or Systemic Abuse of Environmental Law?, 64-111, at <http://www.essex.ac.uk/ebhr/documents/nigerdelta-report.pdf> (accessed 12 May 2018).

10 U.S Government Accountability Office, Deepwater Horizon Oil Spill: Actions Needed to Reduce Evolving but Uncertain Federal Financial Risks, 24 October 2011, 14, at<http://www.gao.gov/assets/590/ 585875.pdf> (accessed 12 May 2018) [hereinafter 'GAO-12-86']. 
obligation' ${ }^{11}$ to compensate affected individuals, suggests that BP has been forced, rather than volunteering, to accept liability in responding to the incident.

Following the GCCF's closure, further questions have been raised concerning the operation's compensatory effects on injured parties, albeit BP paid $\$ 6,667$ million to individuals and businesses through its operation. ${ }^{12}$ Therefore, in In Re: Oil Spill by the Oil Rig "Deepwater Horizon" in Gulf of Mexico on April 20, 2010, the Economic and Property Damages Settlement Agreement, ${ }^{13}$ between BP and the Plaintiffs' Steering Committee, was approved. Through the Court-Supervised Settlement Program, BP estimated the payment of approximately $\$ 7.8$ billion, extending its liability to cover claimants who are not 'class members', ${ }^{14}$ or opt out of the class settlement, via the BP Claims Program, which operates pursuant to OPA 1990, based on the polluter pays principle.

Additionally, BP has filed an acceptance-of-liability statement ${ }^{15}$ as a responsible party of an offshore facility, liable for 'all removal costs plus \$75 million' (OPA $\S 1004$ (d) (33 U.S.C. § 2704)) for natural resource and economic damages. Such a limitation amount is perhaps useless in large-magnitude oil spills like Deepwater Horizon, because they can result in monetary damages extensively exceeding such limits. Nevertheless, since \$2704(c) OPA does not apply in cases involving, amongst others, gross negligence or wilful misconduct, it is thus unsurprising that BP had later voluntarily waived the $\$ 75$ million statutory limit, given the 'regulatory violations" ${ }^{16}$ by the company's management personnel.

Although BP denied any gross negligence on its part, ${ }^{17}$ internal investigations into BP's communication systems revealed that the well was experiencing drilling problems which adversely affected the well's ability to control the oil. ${ }^{18}$ In fact, the drilling process was far behind schedule; every day the drilling was delayed, BP incurred losses exceeding $\$ 500,000$. This factor arguably urged $\mathrm{BP}$ to marginalise its safety and compliance requirements and, to avoid incurring further delay and expense, decided to drill the well 'the fastest possible way' ${ }^{19}$. Yet, the potential of a blowout doubled per every decision that was made to save costs. Moreover, as a UK company bound by the provisions of the Companies Act 2006 (c.46), particularly Section 172, BP's directors should have been more cautious in the degree of supervision applied on the subcontractor's operations onsite. $^{20}$

11 McTyre, N, "Protecting Future Claimants in the BP Oil Spill Matter" SSRN (2011) at <http://papers.ssrn.com/sol3/papers.cfm?abstract_id=1914491> (accessed 12 May 2018).

12 Congressional Research Service, JL Ramseur, REPORT: Deepwater Horizon Oil Spill: Recent Activities and Ongoing Developments, 8, 17 April 2015, at <https://www.fas.org/sgp/crs/misc/R42942.pdf > (accessed 12 May 2018).

13 U.S. District Court, Eastern District of Louisiana, Notice of Filing of the Economic and Property Damages Settlement Agreement as amended on May 2, 2012, and as Preliminarily Approved by the Court on May 2, 2012, 2:10-md-02179-CJB-SS, 2, 3 May 2012, at <http://www.laed.uscourts.gov/sites/default/files/ OilSpill/5.pdf $>$ (accessed 12 May 2018).

14 For a definition of a "class member", refer to U.S. District Court Eastern District of Louisiana (Ibid), 3 (Section 1).

15 U.S. District Court, Eastern District of Louisiana, Statement of BP Exploration \& Production Inc. Re Applicability of Limit of Liability under Oil Pollution Act of 1990, 2:10-md-02179-CJB-SS, 18 October 2010, at <http://www.laed.uscourts.gov/sites/default/files/OilSpill/Orders/BPStatement.pdf> (accessed 12 May 2018).

16 Griggs, JW “BP Gulf of Mexico Oil Spill” 32(1) Energy Law Journal (2011) 57-80, 68.

17 U.S. District Court, Eastern District of Louisiana, supra nt 15, 1-2.

18 Bourne, JK, “The Deep Dilemma” 218 National Geographic (2010) 40.

19 Ibid, 45.

20 Alexander, R, "BP: Protection of the Environment is now to be Taken Seriously in Company Law" 31(9) Co Law (2010) 271-273. 


\section{A superficial response?}

BP's initial response to the damaged well has been criticised as inadequate, because it merely attempted to cap the leakage point when it could have sought for assistance ${ }^{21}$ and failed to prevent the oil from reaching the land. ${ }^{22}$ Conversely, the U.S. Federal Government and BP's corporate responses to oil spill clean-up, remediation and compensation have been characterised as representing 'international best practice ${ }^{23}$ which should be subsequently followed. Notably, BP's refusal to pay a dividend to its shareholders could be justified as responding to pressure by the U.S. Government. However, BP's reputation should not be overlooked; had BP chosen to pay the dividend, it would portray to the public that the incident was part of its 'usual' running of the business. ${ }^{24}$ Overall, it seems that BP showed a clear willingness to respond to the incident and compensate victims, yet the extent to which the courts have regarded this is rather minimal.

It is perhaps fortunate that the responsible party for the oil spill was a giant company like BP, because smaller oil companies are unlikely to have the resources for such a responsibility. Oil spills of the magnitude of Deepwater Horizon can financially exhaust the parties involved if they do not go insolvent, not to mention that only a fractional number of victims would be compensated, counter to the many compensated victims following Deepwater Horizon. Hence, it has been correctly stated that 'BP's unusually deep pockets made appropriate compensation feasible. ${ }^{25}$

\section{B. U.S. federal government}

With regard to the response by the U.S. Federal Government, it has rightfully been argued that Deepwater Horizon was the 'first challenge' ${ }^{26}$ for the oil spill response and containment network intended under the OPA. The Federal Government's claims for response, pollution removal and cleanup rose from $\$ 581$ million to $\$ 626.1$ million within approximately seven months. The Government Accountability Office was concerned that the total expenditures for the Deepwater Horizon, under the government-maintained Oil Spill Liability Trust Fund, could exceed $\$ 1$ billion. ${ }^{27}$ Had this happened, the Government's ability to respond to the ongoing impacts of the oil spill could be adversely affected..$^{28}$ Thereby, members at the $111^{\text {th }}$ Congress with the Government Accountability Office proposed for the removal of the $\$ 75$ million expenditure cap, dependant on BP's

21 Ibid.

22 The New York Times, Robertson, C and Lipton, E, BP Is Criticized Over Oil Spill, but U.S. Misses Chance to Act, 30 April 2010, at <http://www.nytimes.com/2010/05/01/us/01gulf.html?pagewanted= all\&_r=0> (accessed 12 May 2018).

23 Ong, supra nt 9, 102.

24 Alexander, supra nt 20, 272.

25 Viscisi, WK and Zeckhauser, RJ, "Deterring and Compensating Oil Spill Catastrophes: The Need for Strict and Two-Tier Liability" Vanderbilt Law and Economics Research Paper No. 11-27 (2011) at $<$ http://ssrn.com/abstract=1866391> (accessed 12 May 2018).

26 Stefankova, I, "International Regulation v National Regulation on Offshore Oil Exploitation - the USA as an Example" 3 ELSA Malta Law Review (2013) 126-139, 136.

27 U.S. Government Accountability Office, REPORT: Deepwater Horizon Oil Spill: Preliminary Assessment of Federal Financial Risks and Cost Reimbursement and Notification Policies and Procedures, 12 November 2010, 36, at < http://www.gao.gov/assets/100/97169.pdf> (accessed 12 May 2018) [hereinafter 'GAO-1190R'].

28 U.S. Government Accountability Office, REPORT: Deepwater Horizon Oil Spill: Update on Federal Financial Risks and Claims Processing, 18 April 2011, 30, at <http://www.gao.gov/assets/ 100/97443.pdf> (accessed 12 May 2018) [hereinafter 'GAO-11-397R']. 
assurance that it will pay all legitimate claims, or amended where financial recovery can be assured. Overall, this reveals a potential weakness and implication when the U.S. regime is applied to unprecedented disastrous oil spills.

Alternatively, it could be argued that the U.S. regime is capable of tackling large spills, since it encapsulates BP's criminal and civil liability for the oil spill. Indeed, even if an international convention was in place, it will still be periodically amended, because international environmental and energy rules are dynamic instruments, which require gradual amendments to respond to their evolving nature. On another perspective, had the oil spill drifted to cause pollution damage to the Mexican shores of the Gulf of Mexico, the U.S. Government would be the prime body involved with response, cleanup and remediation of environmental damage, not $\mathrm{BP}$, consequently raising international law issues. ${ }^{29}$ Arguably, had a global regime been enforced with specified amounts of liability, the U.S. Government would not be concerned about the continuous loss of funds, because BP's liability would have been fixed under the control of a unified regime. Hence, it has rightfully been argued that the involvement of international environmental law in enforcing an international regime has become a matter of urgency; ${ }^{30}$ Deepwater Horizon has revealed the weakness of coastal States, which face fiscal pressure from the petroleum industry, to prevent and defend against such catastrophic spills.

With regard to the U.S. Federal Government's Claims, following pursuit by the US Department of Justice, BP accepted liability as a responsible party for causing natural resource loss and destruction of over $\$ 75$ million (33 U.S.C. $\$ 2701(20)$ and $\$ 2702(b)(2)$ ), contingently exposing BP to unlimited removal costs and damages (Section 1017(f)(2) OPA 1990, 33 U.S.C. §2717(f)(2); §2717(b); Section 1002(a) OPA, 33 U.S.C. §2702(a)). In United States of America v BP Exploration \& Production Inc et al, BP, as an owner and operator of the offshore facility from which the oil had been discharged, was found liable for civil penalties under Section 311(b)(7)(A) Clean Water Act (CWA 33 U.S.C. $\S \S 1321(\mathrm{~b})(7))$. In addition, BP agreed to pay $\$ 525$ million for violating Sections $10(\mathrm{~b})$ and 13(a) of the Securities Exchange Act 1934 (Securities and Exchange Commission (SEC) v BP $P l c)^{31}$

Overall, whilst U.S. courts settled claims awarding greater damages than English courts, ${ }^{32}$ it has been argued that the U.S. authorities seemed to systematically marginalise BP's corporate interests for the broader public interest. ${ }^{33}$ This perhaps justifies BP's temporary suspension by the U.S. EPA from entering into new contracts with the US government until it had demonstrated compliance with the Federal business standards. ${ }^{34}$ This contract-suspension was arguably used as a weapon against BP, causing it to pay compensation before any official court decision, which posed a contingent financial risk to BP of government monies and opportunities to ensure future earnings. Although the ultimate removal of this suspension highlights that the U.S. Government is satisfied with

29 Ong, DM, Between State Retreat and Intervention: Regulating Environmental Responsibility for Multinational Oil Companies' paper presented at the Workshop on International Law, Natural Resources and Sustainable Development, Scarman House, Warwick University, 11-13 September 2013, 5.

30 Beyerlin, U and Marauhn, T, International Environmental Law (Hart Publishing, Oxford 2011), 442.

31 U.S. Securities and Exchange Commission, U.S. District Court Eastern District of Louisiana, Securities and Exchange Commission v BP plc. 2:12-cv-02774 (E.D. La. Nov. 15, 2012, at <http://www.sec.gov/litigation/complaints/2012/comp-pr2012-231.pdf> (accessed 12 May 2018).

32 Alexander, supra nt 20, 272.

33 Hannigan, B, "Board failures in the financial crisis: tinkering with codes and the need for wider corporate governance reforms: Part 2" 33(2) Comp. Law (2012) 35, 39.

34 U.S. Environmental Protection Agency, BP Temporarily Suspended from New Contracts with the Federal Government, 28 November 2012, at <http://yosemite.epa.gov/opa/admpress.nsf/9cee789b9acd641 685257720005951b7/2aaf1c1dc80c969885257abf006dafb0!opendocument> (accessed 12 May 2018). 
BP's response, this is conditional upon an annual assessment of BP's compliance as to ethics, corporate governance, and process safety. ${ }^{35}$

Corporate liability for BP had since been ongoing; if held strictly liable for each barrel of oil unlawfully discharged into the Gulf of Mexico (CWA, 33 U.S.C. $\$ \S 1251$ et seq), for an amount to be determined by the court (Section 311(b)(7) CWA, 33 U.S.C. $\$ 1321(b)(7))$, BP would face severe financial implications. Moreover, in a recent historic settlement, the oil giant managed to agree with the US Federal Government at a staggering $\$ 18.7$ billion settling outstanding civil penalties and natural resource damages by the U.S. Federal Government and State claims. This agreement is currently being incorporated into a 'proposed consent decree that will be submitted for public comment and then court approval. ${ }^{36}$ If accepted, the figure will sum BP's oil spill charges to $\$ 53.8$ billion, ${ }^{37}$ an amount approximately eleven times greater than Exxon's corporate liability in the 1989 Exxon Valdez oil spill. ${ }^{38}$

\section{A superior response?}

Arguably, the OPA 1990 regime is a strong regime for the global legal community to adopt, although Deepwater Horizon has challenged its liability limits. It is perhaps the offshore oil industry and its legal decision makers' fault that never expected for an oil spill of this magnitude to occur. Moreover, BP's facility-specific oil spill response plan required under the OPA 1990 (33 U.S.C. $§ 1321(j)(5)$ (2006)) for containing the spill proved inadequate, while the effectiveness of the OPA regime vis-à-vis the spill proved ineffective in making BP liable. BP was forced to accept liability and pay compensation well before official court decisions due to unofficial pressure from the Obama Presidential Administration coupled with the need to preserve its reputation. ${ }^{39}$ Nevertheless, the U.S. Government's response has not been 'unduly harsh' ${ }^{\prime 0}$ on BP, but perhaps understandable. BP's insensitive negligence in oil exploration and production delineates the unfair apportionment of liability, which was at the expense of the continuous sufferance and pollution damage to U.S. seas, coastline and to its nationals' deaths. Therefore, the superior response by the U.S. Government was a logical consequence given the prolonged government financial expenditure. Had an international regime been enforceable before the oil spill, liability would be laid at the responsible parties' feet without financially exhausting the State located nearby the offshore oil installation.

Arguably, had the incident occurred in the waters of a lower economically developed State instead of the Gulf of Mexico, the matter would not have engaged the same worldwide interest and popularity. Contrastingly, Tromans and Norris have argued that had Deepwater Horizon occurred west of Shetland, the spill and BP's liability for it would 'inevitably be subjected to far higher levels of public scrutiny. ${ }^{41}$ However, this is

35 Oil \& Gas Journal, Snow, N, EPA lifts post-Macondo contract suspension in agreement with BP, 14 March 2014, at <http://www.ogj.com/articles/2014/03/epa-lifts-post-macondo-contract-suspension-inagreement-with-bp.html> (accessed 12 May 2018).

36 U.S. Department of Justice, Fact Sheet on Agreement in Principle with BP, 1, at <http://www.justice.gov/opa/file/625141/download> (accessed 12 May 2018).

37 The Economist, A costly mistake, 2 July 2015, at <http://www.economist.com/news/business-andfinance/21656847-costly-mistake $>$ (accessed 12 May 2018).

38 Congressional Research Service, Ramseur, JL, REPORT: Deepwater Horizon Oil Spill: Recent Activities and Ongoing Developments, 17 April 2015, 6, at <https://www.fas.org/sgp/crs/misc/R42942.pdf> (accessed 12 May 2018).

39 Ong, supra nt 9.

40 Alexander, supra nt 20, 272.

41 Tromans, S and Norris, J, "What if Deepwater Horizon occurred west of Shetland?" 28(7) International Energy Law Review (2010) 7, 220-227. 
arguably doubtful, given the tremendous corporate accountability imposed on BP by the U.S. and the countless claims for compensation by victims of pollution damage. Nonetheless, it is apparent that the current legal framework surrounding oil spills from offshore installations likens a 'piecemeal' system where there is no concrete international regime. Since domestic laws regulating offshore oil operations in States have been criticised as inadequate (as in the case in question), ${ }^{42}$ poorly developed, or even abused, ${ }^{43}$ an international regime apportioning liability and compensation is highly desirable to effectively tackle future catastrophic oil spills. This can make oil spill responses unreasonably inconsistent and, potentially unfair and unjust. This is in stark contrast to the international legal framework on civil liability and compensation for oil pollution damage by the oil tanker industry, examined below. How, if possible, could this apply to oil spills from offshore oil installations?

\section{Civil Liability System for Oil Pollution Damage by Ships}

...the international regime... is limited to oil spills from...(oil tankers). This deficiency highlights the need for a more comprehensive oil pollution liability regime, since the current international regime would not have covered the Deepwater Horizon incident. ${ }^{44}$

The international liability system currently in place regulates spills from oil tankers under a modern international tort law mechanism, ${ }^{45}$ developed under the auspices of the International Maritime Organization (IMO), to promote the 'universal and uniform application $^{46}$ of instruments to prevent ship pollution, ensuring effective and sustainable shipping. Four Conventions have been developed dealing with pollution damage from oil tankers of which only two are in force, the 1992 International Convention on Civil Liability for Oil Pollution Damage, and the 1992 International Convention on the Establishment of an International Fund for Compensation for Oil Pollution Damage.

\section{A. The three-tier system of compensation}

The primary tier of compensation, the 1992 International Convention on Civil Liability for Oil Pollution Damage (1992 CLC) ${ }^{47}$ is based on strict liability (Article VI(1)) fairly channeled against a registered tanker owner (Article III(1)) caused by loss or pollution

42 Rochette, J, 'Towards an international regulation of offshore oil exploitation' - Report of the experts workshop held at the Paris Oceanographic Institute on 30 March 2012 Working Papers N¹5/12 (IDDRI, 30 March 2012) 6, at <http://www.iddri.org/Publications/Towards-an-internationalregulation-of-offshore-oil-exploitation-Report-of-the-experts-workshop-held-at-the-Paris-Oceanographic$>$ (accessed 12 May 2018).

43 See, for example, Ong, D.M., n.d. Remedying Oil Spills in the Niger Delta: Systemic Failure or University of Essex, Essex Business and Human Rights Project, REPORT: Corporate liability in a new setting: Shell and the changing legal landscape for the multinational oil industry in the Niger Delta,64-111, at $<$ http://www.essex.ac.uk/ebhr/documents/niger-delta-report.pdf> (accessed 12 May 2018).

44 Schoenbaum,TJ, "Liability for Damages in Oil Spill Accidents: Evaluating the USA and International Law Regimes in the Light of Deepwater Horizon" 24(3) Journal of Environmental Law (2012) 395: Schoenbaum recognises the "deficiency" in the international legal community, which lacks a "comprehensive" liability regime that would encompass oil spills from offshore installations.

45 Birnie, P, Boyle, A and Regwell, C, International Law and the Environment (3 ${ }^{\text {rd }}$ ed, OUP, Oxford 2009), 184.

46 International Maritime Organisation, Strategic Plan for the Organization (For the Six-Year Period 2012 to 2017, Resolution A.1037(27), 20 December 2011, 1.1, at <http://www.imo.org/About/ strategy/Documents/1037.pdf> (accessed 12 May 2018).

47 International Oil Pollution Compensation Funds, Liability and Compensation for Oil Pollution Damage, (2011), at <http://www.iopcfunds.org/uploads/tx_iopcpublications/Text_of_Conventions_e.pdf> (accessed 12 May 2018). 
damage of persistent oil from his ship (Article I(6)). Although Article I(6)'s compensatory limitation is a relatively restricted provision, International Oil Pollution Compensation Funds (IOPC Funds) damages are based on the actual amount, rather than 'speculative... theoretical calculations'. ${ }^{48}$ This is at variance with the U.S. Federal Oil Pollution and Clean Water Acts, which provide for unlimited financial liability, potentially exposing $\mathrm{BP}$ to severe monetary implications. Moreover, the channeling of liability is perhaps an unfair apportionment in responsibility, since charterers should also be careful provided they are morally accountable for their corporate activities. ${ }^{49}$ This creates a potential imbalance in the allocation of the financial compensation between tanker owners and oil cargo interests, because the tanker owner will be liable unless the damage was not the result of his own fault (Articles III and V).

Claimants under this primary tier of compensation are provided with a compensatory amount that is proportional to the amount that they have claimed for (Article V(4)). Limits on compensation and liability are applicable, dependent on tanker gross tonnage; for a tanker less than or equal to 5,000 gross tonnage, 4.51 million Special Drawing Rights $(\mathrm{SDR})^{50}$ provides the maximum limit. For tankers with more than 5,000 gross tonnage, 4.51 million SDR with a 631 SDR per additional gross ton and a maximum of 89.77 million SDR. It should, however, be noted that the tanker owner cannot limit his liability if, for instance, he committed an act or omission with the intention to cause pollution damage, or when he acted recklessly and knew that pollution damage would be a potential consequence arising from his act or omission (Article V(2)).

Additionally, compulsory insurance for ship-owners carrying more than 2,000 tons of oil in bulk as cargo (Article VII(1)), or other financial security (Article VII(4)), ensures the ship-owner always has available a financial endorsement contingent on approval of the claim. Indeed, the cooperation of Protection and Indemnity Associations with the IOPC Funds, in assessing each incident and making joint decisions as to claims settlements, ensure a 'consistent and effective approach's1 in this regime.

Overall, the oil tanker regime is global and to a great extent far-reaching; for instance, Article I(8) contains a relatively wide definition of 'incident' that ensures compensation from a mere 'grave and imminent threat' that pollution damage will be caused. Moreover, the fact that the oil tanker regime requires compulsory insurance for ships containing a certain amount of oil cargo (Article VII(1)), helps owners to comply with the provisions under the 1992 CLC. Consequently, although the oil tanker regime might not be a perfect one to adopt for the offshore oil installations industry, in comparison to the current fragmented regime on oil spills from offshore oil installations, the oil tanker regime is arguably far more structured, oriented and uniform in its application.

Arguably, had a similar system to the 1992 CLC been applicable in the offshore oil industry, the extent of financial damages which BP could be exposed to, would be

48 Angélique de La Fayette, L, "New Approaches for Addressing Damage to the Marine Environment" 20(1) The International Journal of Marine and Coastal Law (2005) 167, 201.

$49 \mathrm{Wu}, \mathrm{C}$, Liability and Compensation for Bunker Pollution 33(4) Journal of Maritime Law and Commerce (2002) $553,558$.

50 International Monetary Fund, 'SDR Valuation, at <https://www.imf.org/external/np/fin/data/ rms_sdrv.aspx> (accessed 12 May 2018): SDR is a currency calculated by the IMF on a daily basis.

51 The International Petroleum Industry Environmental Conservation Association (IPIECA)/The International Tanker Owners Pollution Federation Limited (ITOPF), Oil Spill Compensation: A Guide to the International Conventions on Liability and Compensation for Oil Pollution Damage, February 2007, 1, 8, at $<$ http://www.itopf.com/knowledge-resources/documents-guides/document/oil-spill-compensation-aguide-to-the-international-conventions-on-liability-and-compensation-for/> (accessed 12 May 2018). 
considerably lower. This may have been beneficial for BP, though not for the U.S. Government, because although BP would incur damages, the amount of liability and compensation would not be unlimited. However, although the oil tanker regime is not applicable to the offshore oil industry (Articles I, III(1)), the deterrent effect should operate in offshore installations; companies responsible for 'causing immense environmental and economic harm ${ }^{52}$ to States of which companies exploit their natural resources, should face a high amount of liability as a result of their own negligence or misconduct.

The secondary tier of compensation, the 1992 International Convention on the Establishment of an International Fund for Compensation for Oil Pollution Damage $\left(1992\right.$ FC) ${ }^{53}$ automatically binds a Member State which ratifies the 1992 CLC (Article $2(2)$ ), acting as a supplementary provision of compensation funds to the tanker owner where the 1992 CLC is inadequate (Article 2(1)). Compensation limits are not dependent on tanker size but provide for 203 million SDR including the value paid by the tanker owner or his insurer under the 1992 CLC. If this is insufficient to meet all valid claims, the compensation will be proportionately reduced to treat all claimants equally (Article $4(5))$.

The third (optional) tier of compensation, the 2003 Protocol to the International Convention on the Establishment of an International Fund for Compensation for Oil Pollution Damage 1992 (Supplementary Fund) ${ }^{54}$ provides additional compensation of 750 million SDR, including the amounts payable under the aforementioned two Conventions (Article 4(2)(a)). This delineates the advantage of the oil tanker regime; the compensation amount will be adequate for most damage claims, compensation payments will rarely be proportionately reduced and consequently, claimants may receive the whole of their claim. This proportional reduction may, however, be insufficient if applied to an incident as catastrophic as Deepwater Horizon. Moreover, given that only 31 States are parties to the Supplementary Fund Protocol as in August 2017, it is arguably doubtful that this tier of compensation will prove useful to the non-contracting State Parties in the event that an incident of the magnitude of Deepwater Horizon occurs.

\section{B. Small tanker oil pollution indemnification agreement 2006 (STOPIA 2006) ${ }^{55}$ and tanker oil pollution indemnification agreement 2006 (TOPIA 2006)}

These agreements are part of a voluntary 'compensation package ${ }^{57}$ designed to manage the enhanced financial exposure of oil receivers under the Supplementary Fund. STOPIA provides 20 million SDR limitation amount (Clause $\operatorname{IV}(C)(1))$, where the ship does not exceed 29,548 Tons (Clause III(B)(1)), is insured by an International Group of Protection and Indemnity Clubs' member (Clause III(B)(2)) and is reinsured through Pooling arrangements (Clause III(B)(3)). TOPIA provides $50 \%$ contribution of the compensable amount under the Supplementary Fund (Clause $\operatorname{IV}(C))$, where the ship is insured by an International Group of Protection and Indemnity Clubs' member (Clause III(B)(1)).

52 U.S. District Court Eastern District of Louisiana, Complaint of the United States of America v BP, Case 2:10-cv-04536, 2, 15 December 2010, at <https://www.epa.gov/sites/production/files/201310/documents/deepwater-cp121510.pdf> (accessed 12 May 2018).

53 International Oil Pollution Compensation Funds, supra nt 47.

54 Ibid.

55 International Oil Pollution Compensation Funds, Small Tanker Oil Pollution Indemnification Agreement 2006 and Tanker Oil Pollution Indemnification Agreement 2006, 2006, at <https://www.iopcfunds.org/ about-us/legal-framework/stopia-2006-and-topia-2006/> (accessed 27 May 2018).

56 Ibid.

57 Wolfrum, R, "Marine Pollution - Compensation or Enforcement?" in Basedow, J and Magnus, U, eds, Pollution of the Sea-Prevention and Compensation (Springer 2007), 135. 
Albeit liability and compensation seem structured under these agreements, some are not obligatory potentially creating a lack of consistency in or acting unfairly towards the oil receivers' financial exposure in States that have ratified the 1992 CLC and the 1992 Fund Convention but not the Supplementary Fund or the STOPIA/TOPIA 2006.

The USA is a significant maritime State that has not ratified these agreements, perhaps because it prefers to impose its own liability standards. Nonetheless, this stresses the lack of a global unanimous consensus in the oil tanker compensation regime; a negative factor to be considered in assessing whether a similar type of regime should be applied to offshore oil installations. Against the current imperfect and non-uniform, yet structured, framework pertaining to the oil tanker industry, it is arguably essential for the offshore oil industry to establish a regime that is unified under the support of maritime superpower States and balances the interests of all the parties involved.

\section{Is the 'ultimate unification of the current dual system' ${ }^{58}$ the ideal solution?}

Determining whether offshore installations are encapsulated within the 1992 CLC is essential to clarify whether a ship-owner is solely liable, can limit its liability, or whether insurance is compulsory to provide sufficient financial security in the case of a blowout. On the one hand, the U.S. regime under the OPA has been described to be 'broader and more comprehensive' ${ }^{59}$ encompassing oil spills from offshore oil installations and thus the Deepwater Horizon incident. Contrastingly, the oil tanker regime limits its application to oil tanker ship pollution incidents (Article 1 CLC 1992) and thus excludes offshore oil installations.

To assimilate the oil tanker regime to offshore oil installations would result in 'little success' ${ }^{60}$ because oil tankers and offshore oil installations are essentially distinct; offshore units and installation types differ. Notably, the tankers' maximum oil carriage capacity is known, making the risk of prospective spillage calculable. Contrastingly, it is impossible to make such a calculation for oil spills resulting from offshore oil installations since, although the storage capacity of the installation is defined when it is constructed, the amount of oil that can be spilled directly from the well drilled into the marine environment is unpredictable. ${ }^{61}$ Henceforth, international environmental damage caused can be exacerbated through the enhanced duration and magnitude of oil spills from offshore oil facilities.

Furthermore, the right of interpreting the 1992 CLC and Fund Convention is for each Member State, which may cause 'disputes between the member states and the IOPC Fund'. ${ }^{62}$ Additionally, Japan's significant contribution to the IOPC Fund potentially increases its ability to influence decisions. This may create a fear of potential distortion of competition amongst companies in Member States that may strongly oppose Japanese

$58 \mathrm{Kim}, \mathrm{I}$, "A Comparison between the International and US regimes regulating oil pollution liability and compensation" 27(3) Marine Policy (2003) 265, 274.

59 Schoenbaum, supra nt 44, 395.

60 United Nations Environment Program, Scicluna, N, A Legal Discussion on Civil Liability for Oil Pollution Damage Resulting from Offshore Oil Rigs in the light of the Recent Deepwater Horizon Incident, UNEP(DEPI)/MED WG.384/INF.6, 6 June 2013, 54, at <http://www.rempec.org/admin/ store/wyswigImg/file/News/Forthcoming\%20Meetings/Offshore\%20Protocol\%20WG\%20(Malta,\% 2013-14\%20June\%202013/WG\%20384-\%20INF.6\%20-\%20IMLI\%20Doc\%20\%20Dr\%20Sciculna\%20 \%20\&\%20\%20Dr_\%20Guiterrez\%20-\%20E.pdf> (accessed 12 May 2018).

61 Allen, JM, "A Global Oil Stain - Cleaning Up International Conventions for Liability and Compensation for Oil Exploration/Production" 25(1) Australian and New Zealand Maritime Law Journal (2011) 90, 104.

62 Cho, D, "Limitations of 1992 CLC/FC and Enactment of the Special Law on M/V Hebei Spirit Incident in Korea" 34(3) Marine Policy (2010) 447, 450. 
proposals to the IOPC Fund, but which are nevertheless accepted. ${ }^{63}$ Arguably, if an international regime is to be enforced, it should specify rules on equality in decisionmaking to avoid possible influencing of superpower States at the expense of the less economically developed States.

Moreover, the total amount of compensation payable under the 1971 and 1992 Funds (the 1971 Fund being the predecessor to the 1992 Fund) for 135 incidents was U.S. $\$ 860$ million. ${ }^{64}$ In contrast, the single incident of Deepwater Horizon has given rise to figures in billions of U.S. dollars incurred by BP. Hence, had such a regime been applicable to Deepwater Horizon, the aforementioned value would have clearly been inadequate to provide adequate compensation to its victims. Further, even when the limitation limits were reviewed and subsequently increased under the 1992 CLC and FC to U.S. $\$ 310$ million, this figure is still insufficient to cover BP's civil liability and compensation under the incident.

However, it is possible to argue that that is the role of the Supplementary Fund; to cover up in cases where the compensation payable under the 1992 CLC and FC is inadequate. Nonetheless, this argument is unsustainable for two reasons. Firstly, the legal framework under the Supplementary Fund is not enforceable in all States Parties to the 1992 CLC and FC since its ratification/enforcement is optional. The Supplementary Fund can only be applicable in incidents that have occurred after the Supplementary Fund Protocol has been enforced. Therefore, retrospective application of its legal framework by States is forbidden. ${ }^{65}$ Secondly, the compensation available under the Supplementary Fund has also proven inadequate in certain landmark cases. ${ }^{66}$

If the oil tanker civil liability and compensation regime has these disadvantages, why have States preferred acceptance of the 1992 Protocols to the U.S. OPA regime? The simplest answer is that the 1992 Protocols provide for costs that would otherwise be unbearable nationally or regionally. ${ }^{67}$ Arguably, the vast compensatory and liability amounts continuously borne by BP following Deepwater Horizon evince this. Overall, strict liability, compulsory insurance, the ship-owners' entitlement to limit their liability, and the channeling of liability against the registered owner, under the 1992 CLC and Fund Convention, have been advantageous to claimants who are unable to finance expensive litigation.

Finally, this article discusses the partial effectiveness of the current regulatory framework: is there a need to implement and enforce a harmonised international regime?

63 Kim, supra nt 58, 268.

64 Jacobsson, M, "The International Oil Pollution Compensation Funds and the International Regime of Compensation for Oil Pollution Damage" in Basedow, J and Magnus, U, eds, Pollution of the Sea Prevention and Compensation (Springer 2007) 139.

65 International Oil Pollution Compensation Funds, The International Regime for Compensation for Oil Pollution Damage Explanatory Note, August 2017, at <http://www.iopcfunds.org/fileadmin/IOPC_ Upload/Downloads/English/explanatory_note.pdf $>$ (accessed 12 May 2018) [hereinafter 'Explanatory Note'].

66 Jacobsson, supra nt 64, 145.

67 Wall, JF, "Intergovernmental Oil Pollution Activity and Compensation" 17(5) Marine Policy (1993) 473, 477. 


\section{Prospects for the Adoption of an International Civil Liability and Compensation Scheme for Offshore Oil Pollution}

In a technologically advanced and advancing society, regulation alone will not be sufficient, since it will likely be directed to yesterday's problems. ${ }^{68}$

The current 'array of regimes and international agreements' ${ }^{19}$ accentuates that an international civil liability and compensation regime for oil pollution damage would aid the offshore oil exploration and exploitation industry by adding certainty, clarity and harmony. This has the potential to alleviate the complexity of the current framework. The prospects for adopting an international civil liability and compensation scheme for offshore oil pollution incorporate two main dimensions, international and regional, each of which will be discussed in turn, followed by the way forward for the international legal community and the author's proposals for an international regime.

\section{A. The international dimension}

The need to adopt a global framework tackling transboundary offshore oil pollution was regarded at the sixtieth session of the IMO Legal Committee. ${ }^{70}$ Following the Montara incident, the Indonesian delegation made a proposal (LEG/14/1) during the Committee's ninety-seventh session..$^{71}$ Although a uniform global instrument seemed to be the 'preferred solution', ${ }^{72}$ the IMO Legal Committee prompted for an intersessional approach by the Indonesian Government, due to 'procedural and substantive' hurdles. ${ }^{73}$ Overall, there is a general reluctance in implementing an international liability and compensation regime, which is arguably unjustified; energy developing States need a 'safety blanket' that offshore oil operators will be financially accountable to their governments for future oil spills. ${ }^{74}$

The 1982 United Nations Convention on the Law of the Sea (UNCLOS) ${ }^{75}$ provides for this, as under Article 235(1) (Part XII UNCLOS) States are responsible, under international law, to protect and preserve the marine environment. This begs the question of whether an international regime governing oil spills from offshore oil

68 Viscisi and Zeckhauser, supra nt 25: If the international legal community tries to establish an international regime to regulate pollution damage resulting from oil spills from offshore installations, based on the worst incidents up-to-date like Deepwater Horizon, this will be insufficient to address the issue in question. Given that engineering and drilling technologies improve day-by-day, we cannot rely on past incidents, but think of potential future incidents and the potential magnitude they could have. To do otherwise will result in a greater Deepwater Horizon; an incident that was not predicted but was nevertheless the largest marine oil spill in American history.

69 Allen, supra nt 61, 107.

70 International Maritime Organization, Maritime Environment Protection Committee, Report of the Marine Environment Protection Committee on its Sixtieth Session, 12 April 2010, 1.7, at <http://www.gc.noaa.gov/documents/gcil_imo-mepc_60-22.pdf> (accessed 12 May 2018).

71 I Legal Committee 'Proposal to add a new work programme item to address liability and compensation for oil pollution damage resulting from offshore oil exploration and exploitation' (IMO, 10 September 2010) <http://cil.nus.edu.sg/wp/wp-content/uploads/2013/03/Indonesias-proposal-for-a-new-progr amme-to-develop-an-international-regime.pdf $>$ (accessed 12 May 2018).

72 International Maritime Organization Legal Committee, One Hundredth Session of the IMO Legal Committee, 18 April 2013, 4, at <http://comitemaritime.org/Uploads/Publications/ Documents\% 20of $\% 20$ Interest/One $\% 20$ Hundredth $\% 20$ Session $\% 20$ of $\% 20$ the $\% 20$ IMO $\% 20$ Legal $\% 20$ Committee $\% 205$ \%20(1).pdf> (accessed 12 May 2018).

73 Stefankova, supra nt 26, 132.

74 Allen, supra nt 61, 104.

75 United Nations, United Nations Convention on the Law of the Sea, 10 December 1982, 1833 U.N.T.S. 3, 397; 21 ILM 1261. 
installations is needed, because there is none having a globe-wide, uniform and consistent application. Article 235(2) affords States with a wide discretion to introduce national laws concerning compensation following marine environmental pollution; this legal requirement is not on corporations, like BP in Deepwater Horizon.

UNCLOS is a success and marks a significant departure from the 1958 Geneva Conventions by placing States under an express duty to protect, rather than freely allowing them to pollute, the marine environment. However, the UNCLOS regime is potentially problematic, characterised by an element of generality and incomprehensiveness. ${ }^{76}$ In particular, the domestic laws enacted under Article 235 cannot be uniformly harmonised, because some national systems are different or even inadequate compared to others. For example, in Deepwater Horizon the national enforcement against BP by the U.S. Federal Government was persistently strong.

The prospects are still to come, as 'States shall cooperate' (Article 235(3)) in implementing and furthering development of international law regarding compensation and liability from offshore installations. Although UNCLOS provides for this under Article 235, there is no actual universal scheme but there should, arguably, be one; the Convention on Civil Liability for Oil Pollution Damage resulting from Exploration for and Exploitation of Seabed Mineral Resources (CLEE), ${ }^{77}$ examined below, is the closest to this, yet this is a regional and unimplemented Convention.

Moreover, Wolfrum has argued that these provisions within UNCLOS are rather 'embryonic ${ }^{\text {'7 }}$ and lack sufficient clarity, precision and strength that an international regime requires. It might have been an impressive regime during the time UNCLOS was negotiated and adopted; however, given the fast-pacing technological advancement in offshore oil drilling over the last few decades, it is submitted that if a global regime is indeed enforced, it should be periodically amended to reflect the continuous technologically advancing nature of the industry.

\section{B. The regional dimension}

There have been several regional attempts to regulate civil liability and compensation for oil spills from offshore oil installations, each of which will be discussed in turn. To begin with, the Convention on Civil Liability for Oil Pollution Damage resulting from Exploration for and Exploitation of Seabed Mineral Resources (CLEE) has been characterised as a 'forgotten' ${ }^{79}$ attempt to regulate compensation standards of liability. This is rather unfortunate because CLEE has been 'undoubtedly the most important and comprehensive $^{80}$ legal framework on civil liability for oil pollution damage from offshore operations. Article 3 clearly specifies that liability for such damage falls on the installation's operator, subject to explicit exceptions. Moreover, CLEE clearly provides for limited liability, compulsory insurance, and insurance claims. Conversely, Article

\footnotetext{
Tanaka, Y, The International Law of the Sea ( $1^{\text {st }}$ ed, CUP 2012), 263.

16 ILM 1450 (1977).

Wolfrum, supra nt $57,130$.

79 Mediterannean Programme for International Environmental Law \& Negotiation, Raftopoulos, E, Sustainable Governance of Offshore Oil and Gas Development in the Mediterranean: Revitalizing the Dormant Mediterranean Offshore Protocol, 19 August 2010, at <http://www.mepielan-ebulletin.gr/ default aspx?pid $=18 \&$ CategoryId $=4 \&$ ArticleId $=29 \&$ Article $=$ Sustainable-Governance-of-Offshore-Oiland-Gas-Development-in-the-Mediterranean:-Revitalizing-the-Dormant-Mediterranean-OffshoreProtocol> (accessed 12 May 2018).

80 Cornell Law School, Agyebeng, K, Disappearing Acts - Toward a Global Civil Liability Regime for Pollution Damage Resulting from Offshore Oil and Gas Exploration, 20 February 2006, 29, at $<$ http://scholarship.law.cornell.edu/cgi/viewcontent.cgi?article=1026\&context=lps_papers $>$ (accessed 12 May 2018).
} 
15(2) permits the Controlling State's court to apply domestic law to determine whether an operator may limit his liability (Article 6(1)), and the amount of that liability (Article 15(2)). Arguably, this does not ensure harmonisation, because each domestic law varies. If, therefore, this international agreement is to be implemented, it is submitted that domestic courts should be provided with a test for interpreting and applying Article 15(2).

CLEE was aimed to apply to specific States with 'coastlines on the North Sea, the Baltic Sea or that part of the Atlantic Ocean to the north of $36^{\circ}$ North latitude' (Article 18), incorporating Iceland, Sweden and Norway. Hence, it is like there is already a system in place which merely needs to be fully ratified to be effective, yet it will arguably not secure an unvarying application, because States which fall outside of Article 18 will be unable to enforce the Convention. Moreover, CLEE has six signatory States but no parties at all, ${ }^{81}$ thereby remaining unenforceable pursuant to Article 20. However, the reason CLEE has not yet been ratified seems unclear; it could be the lack of enthusiasm (or 'appetite') to ratify it, or that existing bilateral agreements between the concerned States make it unnecessary. Alternatively, State disagreement as to whether the liability limits pursuant to Article 6 should be changed or entirely removed might have been an obstacle in implementing the Convention. Debatably, CLEE is the simplest way for enforcing an international convention for offshore installations, yet its liability limits could be revised and consequently increased.

Had CLEE been applicable to Deepwater Horizon, BP as the operator of the Macondo well would incur liability for any subsequent pollution damage (Article 3). Liability could subjectively be limited to 40 million SDR (Article 6(1)), unless the operator had actual knowledge that oil pollution damage would flow from his own act or omission (Article 6(4)). If this regime was applicable to Deepwater Horizon, BP would arguably be unable to limit its financial liability because the incident was foreseeable, but also preventable, while BP's 'human errors, engineering mistakes and management failures ${ }^{82}$ were primary contributing factors to the disaster. ${ }^{83}$

Furthermore, the Protocol for the protection of the Mediterranean Sea against pollution resulting from exploration and exploitation of the continental shelf and the seabed and its subsoil (Mediterranean Offshore Protocol), ${ }^{84}$ is "comprehensive and ambitious ${ }^{85}$ given the increasing offshore exploration and exploitation undertakings in the Mediterranean Sea. Parties must take any precautionary measures to avoid pollution in other jurisdictions (Article 26). In addition, according to Article 27, Parties should adopt procedural rules regarding liability and apportionment of compensation, (Article 27(1)) such that operators pay 'prompt and adequate compensation' (Article 27(2)(a)) and possess some financial security to ensure the payment of compensation should a damaging activity occur (Article 27(2)(b)). Perhaps, an international regime incorporating Article 27 of the Protocol could be ideal as, provided the international

81 Foreign \& Commonwealth Office, Convention on Civil Liability for Oil Pollution Damage resulting from Exploration for and Exploitation of Seabed Mineral Resources Status List, 1977, at <https://www.gov.uk/government/uploads/system/uploads/attachment_data/file/270187/30._Oil_ Pollution_Damage_1977__Status_list.docx> (accessed 12 May 2018).

82 Rochette, supra nt $42,6$.

83 See, in particular, National Commission on the BP Deepwater Horizon Oil Spill and Offshore Drilling, REPORT: The Gulf Oil Disaster and the Future of Offshore Drilling, 2011, chapter 4, at <https://www.gpo.gov/fdsys/pkg/GPO-OILCOMMISSION/pdf/GPO-OILCOMMISSION.pdf> (accessed 12 May 2018).

84 Official Journal of the European Union, Protocol setting out the fishing opportunities and the financial contribution provided for by the Fisheries Partnership Agreement between the European Union and the Republic of Seychelles, OJ 2013 L004/15.

85 Rochette, supra nt 42, 13. 
environmental framework is a dynamic instrument, it will need to be occasionally reviewed and assessed 'in the light of contemporary developments. ${ }^{86}$ Consequently, the Mediterranean Offshore Protocol delineates that some offshore oil installation areas may be covered by liability and compensation schemes. However, regional application aside, this Protocol has had minimal ratification.

Moreover, the Kuwait Protocol Concerning Cases of Emergency $1978^{87}$ and Abidjan Protocol Concerning Cases of Emergency $1981^{88}$ are regional-seas protocols to the Kuwait Regional Convention for Co-operation on the Protection of the Marine Environment from Pollution (Kuwait Convention) ${ }^{89}$ and the Abidjan Convention for Cooperation in the Protection and Development of the Marine and Coastal Environment of the West and Central African Region (Abidjan Convention).$^{90}$ They apply to the Persian Gulf and West and Central Africa respectively. They require States to cooperate to deal with and respond to marine pollution. Arguably, the Kuwait Convention is more advanced than the Abidjan Convention by clearly providing for an implementation of a civil liability and compensation regime for damage resulting either from the pollution of the marine environment (Article 13(1)), or from the violation of the Convention and its protocols (Article 13(b)).

Overall, these various scattered attempts to tackle civil liability and compensation following oil spills from offshore oil installations have arguably been correctly characterised as 'unconvincing and unsatisfactory'. ${ }^{91}$ Although they leave States with room for flexibility in their application, the fact that each individual State can develop its own regime minimises harmonisation, which is an essential element to a globallyenforceable regime. For instance, Canada has sought to make its national laws stricter ${ }^{92}$ whereas other States' laws are not strict.

In addition, the Offshore Pollution Liability Agreement (OPOL) ${ }^{93} 1975$ effective as of 1 April $2015^{94}$ was an interim measure to the aforementioned CLEE Convention in the form of a private agreement between specific operators of offshore oil and gas facilities, which does not seem to address the urgency for establishing an international regime. It stipulates for strict liability, subject to exceptions (Clause IV(B)), to a limit of U.S. $\$ 250$ million per incident (Clause IV(A)). Such a figure may be well insufficient to tackle large releases of oil; in Deepwater Horizon BP incurred billions of dollars liability, while the prolonged multi-district litigations in Houston ${ }^{95}$ and Louisiana ${ }^{96}$ exposed BP to additional financial liability.

Arguably, OPOL is an incomprehensive agreement mainly because the definition 'Pollution Damage' (Clause I(13)) fails to cover depreciation in the value of the natural

86 Scicluna, supra nt 60, 48.

8717 ILM. 526 (1978).

8820 ILM. 756 (1981).

8917 ILM 511 (1978).

9020 ILM 746 (1981).

91 Scicluna, supra nt 60, 48.

92 Rozmus, A, 'Modernizing Liability for Offshore Oil \& Gas Explorations and Operations' (Bennett Jones LLP, 15 August 2013) < http://www.bennettjones.com/Publications/Updates/Modernizing_Liability_ for_Offshore_Oil__Gas_Explorations_and_Operations/> (accessed 12 May 2018).

93 13 I.L.M. 1409 (1974).

94 The Offshore Pollution Liability Association, Offshore Pollution Liability Agreement ("OPOL"), April 2015, at <http://www.opol.org.uk/downloads/OPOL-Agreement-From-1april2015.pdf> (accessed 25 May 2018).

95 US District Court, Southern District Texas, In Re: Oil Spill by the Oil Rig "Deepwater Horizon" in the Gulf of Mexico on April 20, 2010, MDL No. 2185.

96 U.S. District Court Eastern District of Louisiana, In Re: Oil Spill by the Oil Rig "Deepwater Horizon" in the Gulf of Mexico on April 20, 2010, MDL No. 2179. 
resources caused by the damage to the natural environment. Likewise, it fails to define 'direct loss ${ }^{97}$ which may lead to uncertainties during the filing of compensation claims. Moreover, it seems to have a limited scope of geographical application; the Preamble refers to pollution damage in offshore facilities 'so used and located within the... "Designated State"' (Preamble) yet the definition of a 'Designated State' does not include the U.S., unless it falls under Clause $\mathrm{X}$ amendments for the denomination of another State (Clause I(4)). Contrariwise, OPOL is limited to States around the European area. Hence, OPOL is yet another example of the multiple schemes that have been adopted but like the others, it covers certain areas, leaving other significant maritime regions not encapsulated within these schemes. Furthermore, the one-year time frame within which a claimant may file a claim after the incident (Clause VI) is potentially inadequate; BP received claims for compensation by victims of pollution damage even four years after Deepwater Horizon.

\section{The way forward}

There is a strong outcry for a global instrument regulating offshore exploration and exploitation activities due to the contingent environmental risk of polluting the State in which the installation operates and the neighbouring States. ${ }^{98}$

Clearly, the nature of the current legal framework on offshore oil exploitation is 'fragmented and incomplete' 99 based on diverse treaties and legal instruments. Albeit a similar regime to the oil tanker regime is implemented, it will not entirely face the difficulties in local economic recessions caused by catastrophic oil spills such as Deepwater Horizon. Indeed, the limited compensatory amount available for environmental damage under the oil tanker regime potentially makes restoration of the affected marine and coastal environment difficult.

Alternatively, there is the undecided issue of whether strict liability should apply if such a regime is to be enforced with unlimited liability. A regime similar to the IOPC Supplementary Fund regime could be adopted, funded by the offshore oil industry itself, providing an additional layer of compensation that will be adequate to compensate victims in need of greater liability limitation amounts than the fixed ones, set 'as high as possible'. ${ }^{100}$ Although this may be a good starting point for enforcing an efficient international regime for offshore activities, oil exploration and production corporations may be unwilling to provide such high funding amounts for the regime.

Moreover, the superpower status of States essential to the enforcement of a global regime may oppose its implementation leading to a lack of uniformity in its application. Indeed, the various scattered regional agreements highlight the urgency for a harmonised global instrument tackling civil liability and compensation for oil spills from offshore installations. Each maritime region may require its own approach based on its 'environmental specifications' ${ }^{101}$ which arguably outweighs the need for launching an international regime, yet the enforcement of a relatively flexible international regime could enable its application to those specific areas. Additionally, the challenge faced by States lacking human resources and funds to effectively respond to offshore oil spills, increases the need of adopting a written agreement. The more economically developed

\footnotetext{
97 Ehlers, P, "Origins and Compensation of Marine Pollution - A Survey" in Basedow, J and Magnus, U, eds, Pollution of the Sea-Prevention and Compensation (Springer 2007) 118, 119.

98 Scicluna, supra nt 60, 21.

99 Rochette, supra nt 42, 1, 6.

100 Scicluna, supra nt 60, 55.

101 Stefankova, supra nt 26, 138.
} 
States with the offshore oil industry's contributions are therefore essential to 'envisage a unique convention' ${ }^{102}$ tackling safety and liability issues. Likewise, an international regime will be more resistant to opposition than domestic or regional laws, which can be more flexible and leave room for maneuver, or even where such provisions are nonexistent due to a State's inadequate economic resources.

Albeit the argument that the infrequent occurrence of oil spills from offshore installations has provided an excuse for the worldwide community's failure to agree on a uniform regime, ${ }^{103}$ the Deepwater Horizon was arguably the long-awaited opportunity for the international community to establish an international regime for oil spills from offshore installations, while the ongoing demand for petroleum products poses the potential for a positive correlation to oil spills resulting from offshore activities. Provided that the offshore petroleum industry does not adequately financially contribute in compensating for marine environmental pollution, launching a universal agreement will arguably apportion liability and contribution to compensation on a fairer, just and more reasonable basis compared to the current fragmented regime. Therefore, the broader public interest and affected people who are not compensated in the process should be considered.

Moreover, the continuous lack of a consistent international instrument, highlighted in Deepwater Horizon, can financially exhaust the parties involved due to the ongoing complex litigation until $\mathrm{BP}$ has provided full liability and compensation. Hence, an international convention could be the ideal approach for the establishment of a global regime, but the negotiation and implementation process will take years to be completed, leaving a timeframe filled with 'uncertainty for operators and... diverse and unpredictable reactions from some regulatory bodies. ${ }^{104}$ However time-consuming, the need to internationally address the urgency for a liability and compensation scheme is crucial. Although the international community should 'act promptly', ${ }^{105}$ it is arguably pointless to address this issue if superpower States do not cooperate in its enforcement.

\section{Proposals for an international regime}

Federalising responses to oil spills and merely billing the responsible oil company is not an ideal solution, as governments usually lack the knowledge and the technological advancement that oil companies have. Thus, the proposed regime needs to ensure the smooth cooperation of oil companies in the process and to have an effective and efficient financing mechanism. Arguably, it should be financed by taxes on operators and parties owning, operating or have a financial interest in the offshore oil installation industry, with fixed amounts depending on the size and scale of the offshore oil installation. In this respect, the proposed regime should define an 'offshore installation' widely, as embracing both fixed and mobile installations. ${ }^{106}$ As a response to oil spills, it is usual for governments to spend staggering sums of money for minimizing to the extent possible ecological, environmental and human damage involved whilst knowing that not all of it might be recovered ${ }^{107}$ For this reason, State Parties should be obliged to ensure that the respective taxes are indeed paid into the regime by the respective parties.

\footnotetext{
102 Rochette, supra nt 42, 13.

103 Makuch, KE and Pereira, R, Environmental and Energy Law (Wiley-Blackwell, Chichester 2012), 220.

${ }^{104}$ Cameron, P, "Liability for Catastrophic Risk in the Oil and Gas Industry" 6 International Energy Law Review (2012) 207, 218.

105 Allen, supra nt 61,107.

106 Scicluna, supra nt 60, 55.

107 Viscisi and Zeckhauser, supra nt 25, 7.
} 
A compensation system is important to ensure prompt and adequate compensation to people whose properties have been damaged as a result of humaninduced marine environmental disasters. A liability system should operate and be enforced in a way that deters, or at least minimises the probability of, future human errors. The entire regime should be uniformly interpreted and consistently applied in the manner definitions are interpreted and applied, and in the treatment of compensation claims across all the territorial scope of the regime's application. ${ }^{108}$

In assessing the oil tanker regime above in Part 2, it is perhaps far from perfect for it to be entirely adopted in the proposed regime. For instance, evaluating the definition of 'pollution damage' in Article I(6) 1992 CLC, it is argued that though it is a significant improvement from its 1969 equivalent, it still lacks a sufficient level of precision when it comes to calculating compensation and liability amounts to be paid. Moreover, in contrast to the oil tanker regime where the shipowner tends to be a single party, the proposed regime should take into account that most often, there are multiple, rather than a sole or a predominant owners or operators that may be classified as the responsible parties to an oil spill. ${ }^{109}$ Therefore, the apportioning of liability should carefully be adjusted in a manner that is fair, just and equitable for all the parties involved, according to the percentage of contribution to the oil spill.

The dilemma of whether or not to impose limits on the amounts of corporate liability is important, especially if the regime to be adopted is one of strict liability and compulsory insurance for the operators and other responsible parties. On the one hand, the high insurance premium cover for uncapped liability would mean that offshore oil corporations are going to oppose the proposed regime. Contrariwise and reflecting upon Deepwater Horizon, liability caps can prove to be miserably inadequate to cover the vast liability and compensatory amounts; had these caps been applied in Deepwater Horizon, a significant number of victims would remain uncompensated.

One way to solve this dilemma would be to adopt a similar structure to the tiered system of compensation adopted in the oil tanker industry with the effect that liability caps would exist, but there would be a supplementary tier of compensation which will be triggered as and when liability limits are inadequate to cover all compensatory claims. However, it should be noted that the Supplementary Fund in the oil tanker regime is optional and therefore, not always applicable. Another way to solve the dilemma, as has been proposed, would be to have limits and then revising and updating them according to incidents as they arise. ${ }^{110}$ This is arguably not an ideal solution because it leaves the problem at issue unresolved and other incidents similar to, or worse than, Deepwater Horizon will challenge the practical efficiency and effectiveness of the regime.

Popper argues that capping liability is not corrective justice and undermines public policy, because it does not provide 'just and equitable compensation for victims in a broad range of fields... caps on damages undermine the deterrent effect of tort liability and fail to achieve economically efficient and socially just results. ${ }^{, 11}$ Therefore, capping liability would undermine the overall purpose of a civil liability regime. In Deepwater Horizon, the incredible sums BP paid could potentially deter future oil spills, but as long as the U.S. and other States continue to be dependent on oil as a primary energy

\footnotetext{
108 Jacobsson, supra nt 64, 143-146.

109 Viscisi and Zeckhauser, supra nt 25, 5-6.

${ }^{110}$ Max Planck Foundation for International Peace and the Rule of Law, Mensah, TA, International Oil Pollution Compensation Funds, 2011, 7.

${ }^{111}$ Popper, AF, "Capping Incentives, Capping Innovation, Courting Disaster: The Gulf Oil Spill and Arbitrary Limits on Civil Liability" DuPaul Law Review (2011) at <http://ssrn.com/abstract=1805134> (accessed 12 May 2018).
} 
source, ${ }^{112}$ oil spills are bound to happen; thus, the international legal community should be adequately prepared.

Adopting a uniform international civil liability and compensation regime for oil spills from offshore oil installations with fixed liability amounts will be beneficial for corporations, yet not for State Parties, particularly if the total liability amount exceeds the fixed liability amount under the regime. Considering the towering financial liability borne by BP, such amounts would cause disadvantage and be anti-competitive to smaller offshore oil exploration and production companies, which do not have a similar capital potential like BP and thus cannot self-insure. ${ }^{113}$ Alternatively, it has been argued that small companies that cannot afford such financial implications should not operate. ${ }^{114}$ Given the impossibility of predetermining the full extent of an oil spill from an offshore installation due to its technical specifications, the financial magnitude of the harm remains unknown. However, it is submitted that the responsible party should have the financial capability of rectifying the harm; contrary to the Viscusi-Zeckhauser proposal, 'insufficient resources' ${ }^{115}$ should not provide an excuse for capping liability amounts.

Arguably, had BP been a small company rather than an 'oil giant' in Deepwater Horizon, the majority of victims would remain uncompensated, whilst a significant proportion of the immense amount of expenses incurred by the US Federal Government in response to the oil spill would remain irrecoverable. Hence, such a regime would not provide fairness and justice to the claimants, nor would it take into consideration the broader public interest. This is a forceful argument since recent proposed amendments to Canadian legislation ${ }^{116}$ have purported to increase the absolute liability and financial capacity of companies operating in the Atlantic offshore and the Arctic regions to $\$ 1$ billion, potentially knocking-out smaller private companies operating in the aforementioned regions. Correspondingly, providing the international oil industry comprises of companies with varying business and capital capacity, operators' capacity to pay for oil spillage may not be as competent as was BP's ability to pay the large amount for its liability for Deepwater Horizon. Accordingly, if an international regime is to be proposed, should it be limited to large operators or should it be encompassed across all kinds of operators? The latter could be the ideal option for ensuring consistency and uniformity in its application; however, it might act unfairly towards smaller operators and new market entrants with a lower capital available to pay for such catastrophic risks.

The importance of having insurance has been recognised in the civil liability and compensation regime pertaining to oil spills from oil tankers and is equally important for the offshore oil installations industry, because it ensures the necessary financial security in cases where, for example, the responsible party has insufficient resources to compensate victims of pollution damage. Therefore, victims are safeguarded the payment of compensation. However, that suggests that the insurance premium will be very high. Arguably, the principle of 'make whole', ${ }^{117}$ to compensate victims in a manner that reverts them back to their financial and welfare (human health) position but for the oil spill, is important in the proposed regime. In this process, the causation principle is

112 U.S. Energy Information Administration (EIA), REPORT: Annual Energy Outlook 2015 with projections to 2040, April 2015, figure 18, at <http://www.eia.gov/forecasts/aeo/pdf/0383(2015).pdf> (accessed 12 May 2018).

113 Congressional Research Service, Ramseur, JL, REPORT: Liability and Compensation Issues Raised by the 2010 Gulf Oil Spill, 11 March 2011, 11, at <http://www.fas.org/sgp/crs/misc/R41679.pdf> (accessed 12 May 2018).

114 Ibid.

115 Viscisi and Zeckhauser, supra nt 25, 24.

116 Canada-Nova Scotia Offshore Petroleum Resources Accord Implementation Act, SC 1988 c.28, Canada (1988).

117 Viscisi and Zeckhauser, supra nt 25, 21. 
essential, whilst the burden of proof should perhaps be on the claimant to prove that pollution damage would not have occurred but for the offshore oil spill. In terms of the threshold, a high threshold should arguably be avoided since it will make it difficult for victims to get compensated.

\section{Conclusion}

[Deepwater Horizon] is a direct consequence of our global addiction to oil... Incidents like this are inevitable as we drill in deeper and deeper waters. ${ }^{118}$

This article has examined whether Deepwater Horizon has signalled the need for an international regime to be adopted and enforced, regulating corporate liability and compensation following oil spills from offshore oil installations. The examination of this issue has progressed through three parts, beginning with the corporate liability and compensation issues arising from Deepwater Horizon, showing the weaknesses and the strengths of the U.S. OPA regime. It has been argued that Deepwater Horizon has revealed the limitations in the current fragmented and unconsolidated legal framework pertaining to civil liability and compensation issues arising from oil spills from offshore installations. In my submission, the current regime is inadequate to address important issues of safety, compensation and apportionment of liability.

The argument that oil spills having Deepwater Horizon's magnitude are unlikely to happen is largely unsustainable. Even before Deepwater Horizon, there was a common belief that the probability of an oil spill of such magnitude was fractional, if not inexistent, whilst in the unlikely event of a blowout, the oil spill would not be major. Then, Deepwater Horizon happened; the magnitude of it and the billions of dollars spent in response to it proved the contrary. The time has come for the international legal community to act; deepwater drilling and the continuous dependence on, and demand for, oil means that further disastrous incidents like Deepwater Horizon, or even worse, will always pose an imminent threat. Arguably, Deepwater Horizon was the long-awaited call for the establishment of an international regime that is similar to the 1992 CLC and the supplementary IOPC Funds regime currently in force regarding pollution damage from oil tankers, which has been discussed in Part 2, applicable on a compulsory basis regarding insurance, corporate liability and compensation. If a regime similar to the oil tanker regime is implemented covering oil spills from production wells, it should have structural differences that would make it consistent with the varying specifications of tanker vessels and offshore installations.

In examining the prospects for adopting an international regime regulating civil liability and compensation following oil spills from offshore installations, this article proposed for a practically efficient and effective regime with universal consensus. It would bring advantages for under-developed and developing States in standing up to transnational corporations and can help small companies and new market-entrants with fewer financial resources. There will be no room for exploitation and maneuvering the regime that may, at times, allow corporations to disregard victims. Henceforth, global environmental governance will be sharpened by the collective contribution of politicians and scholars in international law to safeguard the marine environment from ruinous oil spills, by bridging the gaps within the current fragmented and deficient legal framework. Optimistically, re-assessing the legal framework pertaining to corporate liability and

118 Bourne, supra nt 18, 53. 
182 GroJIL 6(1) (2018), 161-182

compensation applicable to oil spills from offshore oil installations may prove to be merely the beginning. Nevertheless, the international environmental law's contribution in tackling the on-going global environmental crisis has become a matter of urgency. The recent Deepwater Horizon oil spill, being the most catastrophic accidental release of oil from an offshore oil installation in the marine environment in American history, has highlighted the need for international law to target corporate liability and compensation issues following oil spills from offshore installations.

www.grojil.org 